\title{
Motivation of infection control in nurses' viewpoint
}

\author{
Diana Platace, Kristine Puzirevska, Amanda Kreile, and Inga Millere \\ Rīga Stradinsš University, Riga, Latvia
}

\begin{abstract}
The spread of hospital infections in high-risk units remains even though infection control and prevention measures are being improved annually. It is associated with factors such as age, severity of the underlying disease, duration of hospitalization, antibacterial therapy, resistance to microorganisms, and the number of invasive procedures. The human resources and the financial distribution in medicine play the key role in controlling infections. Intensive care nurses supervising and taking care of the patients 24 hours a day have an invaluable role in controlling infections and reducing hospital infections. The aim of the study is to find out the nurses' opinions about the factors motivating infection control in the intensive care units and in the department of internal medicine. The study used a quantitative study method-survey $(n=160)$. The questionnaire included questions about the factors influencing infection control and the factors motivating the nurse. Questionnaires involved nurses in the intensive care units and in the department of internal medicine, who care for patients in Latvian multifunctional regional hospitals. The study suggests that nurses are motivated by both material and non-material motivating factors. The material motivating factors in nurses' viewpoint are maintenance of workplace, the premium of work quality, the premium for night work and overtime, premium for work on holidays, possibility to attend courses and training, vacation pay, as well as environment of work. The nonmaterial motivating factors in nurses' viewpoint are the attitude of the supervisor, being respectful of their workplace, the relations with colleagues, acknowledgment for the work done, the responsibility at work, the pride and respect for the work to be done, the challenges, interesting job and variety in work tasks, as well as the growth and development in the workplace.
\end{abstract}

\section{Introduction}

Regardless of the great advances in medicine, 5-10\% patients, who are admitted to the hospital, get infections of various degrees, causing serious economic problems and high mortality rate in all countries in the world $[1,2]$. However, there exist various factors which may influence it, for instance, infection control organization in the hospital, nursing workload, material-technical supply, guidelines and documentation of the care, as well as nurses' knowledge, attitude and motivation [3-6]. As a result, more and more attention in hospitals is focused on such infection control measures as hand hygiene, patients' isolation and threshold precautions, decontamination of objects and equipment, cautious use of antibiotics, as well as decontamination of the environment. That allows revealing and preventing the spread of causative agents of infection timely, and increases the effectiveness of patient care, and decrease the treatment costs [7]. A prerequisite of a well-functioning system is a wellmotivated workforce. The study of hospital staff motivation is therefore vital in the practice of 
infection control. To understand motivation, it is worthwhile to investigate the role of social power in infection control. Social power is defined as the potential ability of an influencing agent to change the cognitions, attitudes, or behaviour of other person (the target). The pioneers in the study of social power in infection control were the workers in the Study on the Efficacy of Nosocomial Infection Control (SENIC) project [8]. SENIC has proved that correct and qualitative infection control in the hospital radically reduces the economic costs and increases the quality of the care of hospitalized patients. Moreover, the motivation of nurses is the main precondition for qualitative patient care. Motivation is a complex concept and many theories exist that describe and analyse workers' motivation [9]. In the 1950s, psychologist Frederick Erling Hercberg (USA) formulated one of the first concepts of job satisfaction. The most important factors in the work are growth or internal motivating factors: achievements, appreciation for success, work itself, responsibility, growth and promotion. The relevance of Herzberg's theory for Human Resources Management (HRM) is the need to clarify whether the problem being addressed is mainly one of job satisfaction or one of job dissatisfaction, and then to select the appropriate personnel management strategies. For example, attending to salary levels and working conditions will primarily reduce job dissatisfaction and therefore increase staff retention. To improve motivation and thereby increase staff performance, attention should be given to motivating factors, for example by increasing the individual's sense of achievement, and to demonstrate recognition of that achievement [10]. The choice of the human profession is based on orientation and social values. The choice of profession may also be influenced by the need for certain activities, abilities, resistance to adverse conditions, operating style, and motives [11]. Thus, the motivation of nurses can be affected by some psychological factors, such as attitudes, habits, stress and tolerance. Motivation is internal and external, and is characterized by three features - direction, effort and perseverance [12].

Satisfaction with the work shows how the employee evaluates their work. Employees who are happy with the job, willingly cooperate with colleagues and other departments, take on additional responsibilities and encourage others to work harder [13]. In 12 studies with 1687 employees (2007), the results show that motivation factors are the main reason for job satisfaction. In Brazil (2016), one of the hospitals carried out a study of work satisfaction and motivation to work in a hospital. The results of the study showed that most of the surveyed medical professionals were satisfied with their work in the hospital and the chosen profession, claiming that if they had the opportunity to start their career again, they would again choose the medical profession and the particular specialty. Most of the respondents mention the prestige of the profession as the main choice of profession, but the choice of the workplace is based on the academic environment or the connection of the medical school to the particular hospital where the study was conducted [14]. Studies in Greece, Vietnam and Cyprus show that employees' motivation is influenced by both material and non-material factors, included external and internal motivation. The most common motivator in the survey was the achievements, appreciation from colleagues and the attitude of the supervisor, the work process, the respect that corresponds to levels 4 and 5 of Maslow's hierarchy of needs self-esteem and self-fulfilment. In the second and third place external incentives - salary, working conditions, relationships with colleagues, leadership, job stability - were identified, which in turn correspond to levels 2 and 3 of Maslow's needs pyramid - the need for security and the need for belonging and love $[15,16]$. The results of a study in India show that the most motivated staff in the tertiary care hospital are nurses. They are mainly motivated by responsibility at work, appreciation for their achievements, positive assessment of their abilities and work experience from their colleagues and manager, but the least motivating factors were fear of failure in front of others, competition, challenges and busy work or big 
workload [17]. In 2010, a study in Ethiopia (Negussie, 2012) on motivation for nursing work was carried out. Of the 230 respondents, most noted pay as the most influential factor in terms of job motivation. The second most frequently mentioned answer was promotion at work and third place- recognition. Those are the external and internal factors (incentives) dominating the motivation of Ethiopian nurses [18].

The aim of the research was to explore the nurses' opinions about the factors motivating infection control in the intensive care units and in the department of internal medicine. The study used quantitative study-questionnaires $(n=160)$. Questionnaires involved 60 intensive care nurses and 100 internal medicine nurses in Latvia's regional multi-profile hospitals. The tasks of the research were:

1. to create a questionnaire with an aim to find out the motivating factors and to reveal nurses' opinions about the factors motivating infection control in patient care, as well as about the disturbing factors of motivation to perform infection control in the intensive care units and in the department of internal medicine,

2. to perform research in Latvia's regional multi-profile hospitals,

3. to summarize and to analyze results, as well as compare them with other studies,

4. to make conclusions and to prepare proposals.

\section{Material and methods}

The research was performed in Latvia's regional multi-profile hospitals, and included the intensive care units and the department of internal medicine. The study results were acquired by quantitative study method- survey (nurses in the intensive care units, $n=60$ and in the department of internal medicine, $n=100$ ), where was used the authors' devised and approved questionnaire. The research questions were based on Abraham Maslow's theory illustrated as "Maslow's Pyramid of Needs" and Frederick Erling Hercberg's twofactor theories. The questionnaire included both closed and semi-closed questions with multiple answer options and used the Likert scale. The inclusion criteria for study were nurses in the intensive care units and in the department of internal medicine, who perform infection control in patient care. The exclusion criteria for study were nursing students or other specialists in patient care. Validity of the structured questionnaire was determined by internal coordination coefficient of Alpha Kronbah test significance calculation and it was higher than 0.6. In total, 200 questionnaires were distributed, from them only 160 were returned. In the study were included 160 completely filled in and valid questionnaires.

\section{Statistical analysis of the data}

The quantitative data analysis used in the research work included statistical calculations, making summaries of the obtained data, compared different information and generalized the obtained results, analyzing the cause-effect relationship. The groups of motivating factors (material and non-material) were compared and analyzed. The data were encoded and entered in the computer programme MS Excel table made. After that the data were converted into the programme SPSS for Windows 16.0 (company SPSS, USA) for further statistical analysis. The necessary calculations were done in correspondence with the data structure. All nominal scale and categorized parameters were calculated by the absolute and relative frequencies. Numeral variables were expressed as mean with standard error. For categorical variables, absolute numbers and percentages were shown. 


\section{Results}

Respondents' work experience in the intensive care units was from 1 to 35 years, but the mean time was 7.3 years. Respondents' work experience in the department of internal medicine was from 1 to 40 years, but the mean time was 12.7 years. Most of the nurses worked on average between 160-250 hours per month. According to the laws of the Ministry of Welfare of the Republic of Latvia (2008-2012), the number of hours worked may not exceed 160 hours per month in order to avoid overload of employees.

As a motivating factor for the implementation of infection control in practice intensive care nurses noted the sense of responsibility in patients care $(92 \%)$, care for the patient's health $(82 \%)$, as well as taking care of their own health $(73 \%)$ and their colleagues' health $(60 \%)$. Essential motivating factors were adequate salary, limitations of the spread of infection (adequate infection control and monitoring in high risk units) and faster patient recovery was noted by $60 \%$ of nurses. Motivating factors that directly influence infection control was adequate workload (58\%). Psychological motivation factors, such as fear of being infected and rewarding for good work, were noted by $53 \%$ of nurses. Less mentioned motivating factors were improving the quality of patient care (38\%), ensuring the effectiveness of infection control (27\%) and necessary equipment (23\%), as well as improvement of infection control statistics (13\%) (see Fig. 1).

In the questionnaire, suggestions offered by nurses for motivation included maintenance of workplace (marked "mostly" and "definitely" - 64\%), quality of work premium (41\%), premium for night work and overtime $(41 \%)$, premium for work on holidays $(38 \%)$, possibility to attend courses and training (36\%), vacation pay (32\%), health insurance and social guarantees (31\%), as well as environment of work (28\%). Results obtained by the questionnaire showed that salary for $39 \%$ of nurses does not contribute to their motivation, as well as $62 \%$ of respondents noted that outside of work activities and health insurance, social guarantees $(27 \%)$ do not at all promote their motivation to work as a nurse. The motivating material factors mentioned ("a little" and "average") by nurses were work environment (32\% and $31 \%$ ), premium for work on holidays (26\% and 30\%), premium for night work and overtime ( $25 \%$ and $28 \%$ ), premium for work quality ( $25 \%$ and $27 \%$ ), possibility to attend courses and training (19\% and $36 \%$ ), salary (23\% and $22 \%$ ), vacation pay (20\% and $35 \%)$, as well as health insurance and social guarantees (24\% and 18\%) (see Table 1).

As seen from the obtained results, which are depicted in Table 2, the non-material motivating factors mentioned ("mostly" and "definitely") by nurses were: being respectful of their workplace (53\% and $18 \%$ ), the attitude of the supervisor (45\% and $21 \%$ ), the relations with colleagues ( $43 \%$ and $16 \%)$, acknowledgment for the work done (42\% and $12 \%)$, the responsibility at work $(32 \%$ and $9 \%)$, the pride and respect for the work to be done $(32 \%$ and $8 \%)$, challenges, interesting job and variety in work tasks $(20 \%$ and $35 \%$ ), as well as the growth and development in the workplace (32\% and $8 \%$ ). Results of study of non-material motivating factors obtained by the questionnaire showed that challenges, interesting job and variety in work tasks for $20 \%$ of nurses do not contribute to their motivation, as well as the pride and respect for the work to be done (15\%) and growth and development in the workplace (14\%) do not contribute to nurses' motivation. The non-material motivating factors mentioned ("a little" and "average") by nurses were clearly defined job responsibilities and goals (13\% and 46\%), the growth and development in the workplace $(27 \%$ and $24 \%$ ), responsibility at work $(20 \%$ and $31 \%$ ), the pride and respect for the work to be done (24\% and $21 \%)$, the challenges, interesting job and variety in work tasks (18\% and 24\%), acknowledgment for the work done (12\% and $31 \%)$, as well as relations with colleagues, health insurance and social guarantees (13\% and 27\%) (see Table 2). 


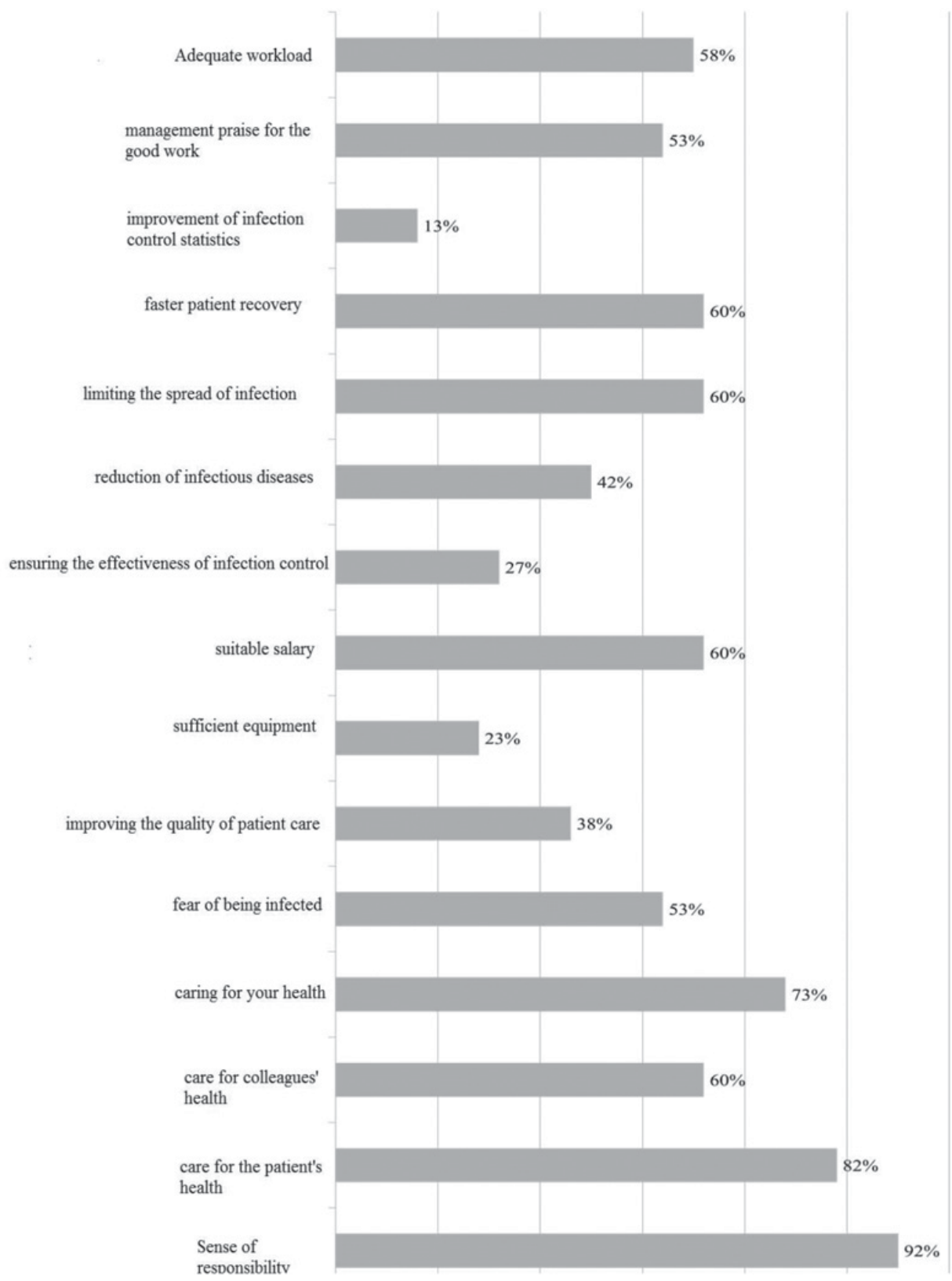

Fig. 1. Motivating factors of infection control in nurses' viewpoint.

\section{Discussion}

The study suggests that nurses are motivated by both a material and non-material motivating factors. Mostly, the motivation of nurses is promoted by non-material or internal factors rather than by material factors. The data from the study shows that the material factors that mostly motivate nurses in the hospitals in Latvia to work in the intensive care units and in the department of internal medicine and to provide infection control are the maintenance of 
Table 1. Material motivating factors in nurses' viewpoint.

\begin{tabular}{|l|c|c|c|c|c|}
\hline Material motivating factors & no & a little & average & mostly & definitely \\
\hline Salary & $39 \%$ & $23 \%$ & $22 \%$ & $11 \%$ & $5 \%$ \\
\hline Environment of work & $9 \%$ & $32 \%$ & $31 \%$ & $21 \%$ & $7 \%$ \\
\hline Maintenance of workplace & $5 \%$ & $13 \%$ & $18 \%$ & $53 \%$ & $11 \%$ \\
\hline Premium of work quality & $7 \%$ & $25 \%$ & $27 \%$ & $36 \%$ & $5 \%$ \\
\hline Health insurance and social guarantees & $27 \%$ & $24 \%$ & $18 \%$ & $21 \%$ & $10 \%$ \\
\hline Premium for work on holidays & $6 \%$ & $26 \%$ & $30 \%$ & $28 \%$ & $10 \%$ \\
\hline Premium for night work and overtime & $6 \%$ & $25 \%$ & $28 \%$ & $30 \%$ & $11 \%$ \\
\hline Possibility to attend courses and training & $9 \%$ & $19 \%$ & $36 \%$ & $25 \%$ & $11 \%$ \\
\hline Vacation pay & $13 \%$ & $20 \%$ & $35 \%$ & $25 \%$ & $7 \%$ \\
\hline Activities outside work & $62 \%$ & $14 \%$ & $16 \%$ & $6 \%$ & $2 \%$ \\
\hline
\end{tabular}

Table 2. Non-material motivating factors in nurses' viewpoint.

\begin{tabular}{|l|c|c|c|c|c|}
\hline Non-material motivating factors & no & a little & average & mostly & definitely \\
\hline Clearly defined job responsibilities and goals & $9 \%$ & $13 \%$ & $46 \%$ & $28 \%$ & $4 \%$ \\
\hline Relations with colleagues & $1 \%$ & $13 \%$ & $27 \%$ & $43 \%$ & $16 \%$ \\
\hline Attitude of the supervisor & $2 \%$ & $5 \%$ & $27 \%$ & $45 \%$ & $21 \%$ \\
\hline To be respectful of your workplace & $6 \%$ & $8 \%$ & $15 \%$ & $53 \%$ & $18 \%$ \\
\hline Acknowledgment for the work done & $3 \%$ & $12 \%$ & $31 \%$ & $42 \%$ & $12 \%$ \\
\hline $\begin{array}{l}\text { Challenges, interesting of job and } \\
\text { variety in work tasks }\end{array}$ & $20 \%$ & $18 \%$ & $24 \%$ & $31 \%$ & $7 \%$ \\
\hline Pride and respect for the work to be done & $15 \%$ & $24 \%$ & $21 \%$ & $32 \%$ & $8 \%$ \\
\hline Responsibility at work & $8 \%$ & $20 \%$ & $31 \%$ & $32 \%$ & $9 \%$ \\
\hline Growth and development in the workplace & $14 \%$ & $27 \%$ & $24 \%$ & $31 \%$ & $4 \%$ \\
\hline
\end{tabular}

workplace, the premium for quality of work, the premium for night work and overtime. There are also material factors that does not affect nurses' motivation, such as salary and outside of work activities (sports games, excursions, etc.), as well as health insurance and social guarantees in nurses' practice of the intensive care units and in the department of internal medicine. Comparing the survey results with the Ethiopian study in 2010, where salary was identified as the most motivating factor [18], as well as in Greece, Cyprus and Vietnam, where it was highly appreciated, it can be concluded that in Latvia the salary of nurses is not so high as to be able to motivate $[10,15,16]$.

The results of the study show that the non-material factors that mostly motivate nurses to work in patient care are relationships with colleagues, the attitude of the supervisor, to be respectful of their workplace and acknowledgment for the work done. Also pride and respect for the work to be done and challenges, interesting of job and variety in work tasks mostly motivate nurses to work in the chosen profession.

Data from the study shows that nurses' motivating factors in the hospitals in Latvia are workload intensity, salary and working time, night work. The results of a study carried out 
in India show that the motivation of nurses working in hospital is also the least favoured by challenges and busy work [17]. Also, in Cyprus and China, job dissatisfaction is due to salary, lack of training and difficult working conditions $[8,16]$.

Human resources are very important components in health care system and, in order to achieve much better public health indices, it is not enough to have modern technologies or new medicines. World Health Organization (WHO) in its report has pointed out that these are people who are the basis of the health service in the 21 st century, emphasizing that the crisis of human resources in medicine is seen worldwide. Besides, one can see a tendency for the decrease in time spent in hospital. Thus, in the period from 1980-2000, the mean time spent in hospital has decreased by 7.5 bed days to 4.9, causing greater care load to nurses because the patient care level is higher. Nurses' amount of workload includes not only the number of nurses per certain number of patients' beds, but also monthly workload and length of the duty, the authors' study data showed, that the nurses' workload in high risk units in Latvian regional hospitals was not limited to 1 workload per month. Nurses worked on average between 160-250 hours per month. According to the laws of the Ministry of Welfare of the Republic of Latvia (2008-2012), the number of hours worked should not exceed 160 hours per month in order to avoid overload of employees. AHRQ (Agency for Healthcare Research and Quality) financed research, carried out in 1993 in 10 countries in the world and covered 589 hospitals, revealed that in the estimates of nurses' workload, adding to the nurse's workload half an hour per 1 patient a day decreased the morbidity with pneumonia in surgical patients by $4 \%$. It is an essential financial profit, if we take into account the fact that if pneumonia follows the underlying disease it may increase the patient's treatment costs by 28000 dollars [19-21]. On the other hand, Pittet and co-authors' studies revealed that due to the staff's workload nurses cannot do proper hand hygienic washing, which for a nurse in intensive care ward makes up to at least 22 episodes per hour, but for the nurse in other ward (for example, surgical and internal medicine departments) - 17 episodes per hour, comparing to the hand hygienic disinfection with alcohol-containing solution [22].

\section{Conclusions}

The study suggests that nurses are motivated by both material and non-material motivating factors. Mostly, the motivation of nurses is promoted by non-material or internal factors rather than by material factors. The material motivating factors in nurses' viewpoint are maintenance of workplace, the premium of work quality, the premium for night work and overtime, the premium for work on holidays, possibility to attend courses and training, vacation pay, as well as environment of work. The non-material motivating factors in nurses' viewpoint are the attitude of the supervisor, being respectful of the workplace, relations with colleagues, acknowledgment for the work done, the responsibility at work, the pride and respect for the work to be done, the challenges, interesting job and variety in work tasks, as well as the growth and development in the workplace. The study suggests that nurses are also motivated by high sense of responsibility and care about patients, colleagues and their own safety, especially in the intensive care units. And at the same time, there are also material and nonmaterial factors that do not affect nurses' motivation, such as salary and outside of work activities, as well as health insurance and social guarantees.

\section{References}

[1] M.W. Stanton, M.K. Rutherford, Agency for Healthcare Res. Quality 14, 1-12 (2004)

[2] S. Dasgupta, S. Das, N.S. Chawan, A. Hazra, Indian J. Crit. Care Med. 19(1), 14-20 (2015) 
[3] D. Gould, E. Ream, J Adv. Nursing 19, 1121-1131 (1994)

[4] S. Hugonnet, J.C. Chevrolet, D. Pittet, Critical Care Med. 35(1), 76-81 (2007)

[5] E.A. Jenner, C. Mackintosh, G.M. Scott, J. Hospital Infect. 42, 91-104 (1999)

[6] A. Minnaar, Infection Control Made Easy: A Hospital Guide for Health Professionals. Professional Nurse Series (Juta and Company Ltd., 2008)

[7] J. Wilson, Infection control in clinical practice, $3^{\text {rd }}$ ed. (London, Elsevier, 2006)

[8] W.H. Seto, T.Y. Ching, Y.B. Chu, W.L. Seto, Am. J. Infect. Control 19(1), 42-44 (1991)

[9] L. M. Franco, S. Bennett, R. Kanfer, Social Sci. Med. 54, 1255-1266 (2002)

[10] M. Dieleman, P.V. Cuong, L.V. Anh, T. Martineau, Human Res. Health 1, 10 (2003)

[11] F. Herzberg, Harvard Business Rev. 81(1), 87-96 (2003)

[12] K. Mārtinsone, A. Miltuze, D. Voita, E. Čukurs, S. Mihailova, I. Damberga, M. Biseniece, A. Hofmane, Psiholoúija 1 (Rīga, Zvaigzne ABC, 2015)

[13] K. Mārtinsone, A. Miltuze, D. Voita, E. Čukurs, S. Mihailova, I. Damberga, M. Biseniece, A. Hofmane, Psiholoíija 3. Lietišiāa jomas (Rīga, Zvaigzne ABC, 2015)

[14] P.O. Vasconcelos Filho, M.R. Souza, P.E. Mangeon Elias, A.L. D’ Ávila Viana, Human Res. Health 14, 75 (2016)

[15] N. Kontodimopoulos, V. Paleologou, D. Niakas, BMC Health Ser. Res. 9, 164 (2009)

[16] P. Lambrou, N. Kontodimopoulos, D. Niakas, Human Res. Health 8, 26 (2010)

[17] P. Jaiswal, A.K. Singhal, A.K. Gadpayle, S. Sachdeva, R. Padaria, Indian J. Commun. Med. 39(4), 235-240 (2014)

[18] N. Negussie, Ethiopian J. Health Sci. 22(2), 107-112 (2012)

[19] M.W. Stanton, M.K. Rutherford, Agency for Healthcare Res. Quality 14, 1-12 (2004)

[20] S.H. Cho, S. Ketefian, V.H. Barkauskas, et al., Nurs. Res. 52(2), 71-9 (2003)

[21] J. Needleman, P. Buerhaus, S. Mattke, et al., N. Engl. J. Med. 346(22), 1715-22 (2002)

[22] D. Pittet, J.M. Boyce, Lancet Infect. Dis. 4, 9-20 (2001) 